\title{
Determinants of Vulnerability to Food Insecurity in a South African Township: A Gender Analysis
}

\author{
Fumane Ndobo \\ School of Economics, \\ North-West University, Vanderbijlpark, South Africa. \\ Tshediso Joseph Sekhampu \\ School of Economics, \\ North-West University, Vanderbijlpark, South Africa. \\ E-mail: joseph.sekhampu@nwu.ac.za
}

\section{Doi:10.5901/mjss.2013.v4n14p311}

\section{Abstract}

\begin{abstract}
The results of a study reported in this article comparatively analyse the gender determinants of vulnerability to food insecurity in a South African township of Kwakwatsi, South Africa. The results are based on a household survey using questionnaires. A multiple regression model was estimated based on this data with the household food security status (household food insecurity access score) as the dependent variable and a set of demographic variables as explanatory variables. It was found that about 49 per cent of the sampled households are vulnerable to food insecurity. Food insecurity was more prevalent in female-headed households (63.8\%) compared to male-headed households (42.9\%). The results of the regression analysis indicates that in male-headed households, vulnerability to food insecurity increases with age of the household head but it would decrease with an increase in household income and the employment status of the household head. In female-headed households vulnerability to food insecurity increases with marital status, household size and age of the household head, while it decreases with household income. This study is at household level and makes a contribution to empirical literature by modeling the factors which determine food insecurity in a South African township.
\end{abstract}

Keywords: Food insecurity; determinants; gender; township; South Africa.

\section{Introduction}

South Africa is a middle income country characterized by large income inequalities and absolute poverty (Altman et al., 2009:7). Since the early 1990s food security in South Africa has always been a topic of interest particularly in the light of occurrence of the droughts on the sub-continent (Van Zyl, 1992:2). Since the political transition in 1994, the country has been self-sufficient in supplying and distributing adequate food even when there have been shortages in import supplies (Department of Agriculture, 2011:4). South Africa's political history has played a major role to the challenges of poverty and food insecurity evident in many parts of the country. The African majority were not given equal opportunities in terms of education and self-recognition as compared to the white population, thereby contributing to household food insecurity (Department of Agriculture, 2002). Almost two decades after the political transition, the country still experiences food insecurity both in rural and urban areas. The lower incomes and rising unemployment limit access to food for the poor (Labadorios et al., 2009:11). Although it is estimated that the hunger rates have declined from 24\% in 2002 to $12 \%$ in 2011, statistics indicate that one in five households cannot access sufficient food (Stats SA, 2011). Furthermore, almost a half of households in rural areas experience inadequate access to food as compared to urban households (Department of Agriculture, 2012). The rise in the cost of food prices is one of the contributing factors to food insecurity in South Africa; since 2008 the average price of food items has been rising faster than the economy's consumer inflation level (Ackerman, 2012).

The Reconstruction and Development Programme formulated in 1994 acknowledged food security as one of its top priority for policy objective. Further policy interventions includes the Integrated Food Security Strategy adopted in 2002, however much still needs to be done to improve the level of household food security (Department of Agriculture, 2012:3). Von Braun et al. (1992) alludes that household food security monitoring requires disaggregated consumption information at the household level, based on surveys. They further argue that socio-economic, demographic and 
nutritional variables can complement programs that monitor changes in household food security. Several studies have been undertaken in order to understand household food security. Arene (2008) found that household income and the age of the household head are important determinants of food security. A study by Bashir et al. (2012) in Pakistan concluded that household's monthly income and household head's education levels were positively impacting household food security. On the other hand, household heads' age and family size were negatively associated with household food security. The African Food Security Urban Network (AFSUN) conducted a food security survey of 11 Southern African cities. Their studies found strong links between urban poverty and high levels of food insecurity at the household level (Crush et al., 2012).

Several studies have argued that female headed households are more likely to be vulnerable to food insecurity and poverty as compared to their male counterparts (Kassiel et al., 2012:5). Carter et al., (2012:7) found that incidents of food insecurity are much higher in female headed households compared to male headed households. Females are most likely to be single parents than their male counterparts and this increases the burden of taking care of the needs of a household. A study conducted by Kassie et al. (2012:14) in Kenya concluded that the change in chronic food insecurity between female-headed households and male-headed households is statistically significant. The study found that almost $53 \%$ of male-headed households were food secure compared to $42 \%$ of female-headed households. Franye (2009:16) found that among the three biggest cities in South Africa, female-headed households were hit the hardest by the incidents of food insecurity as compared to male-headed households. These studies demonstrate a need to untangle the problem of food security from different perspectives. This study extends on these findings by providing a gender based analysis of determinants of household vulnerability to food insecurity in a South African township. This study attempts to provide quantitative evidence at a micro level by analysing the impact of socio-economic and demographic variables of a household on its vulnerability to food insecurity. The results of this study can be used as a reference source when setting programmes relating to poor urban residents in a township setting in South Africa. Identification of the characteristics of households likely to be vulnerable to food insecurity can allow for targeted food security strategies. The next section is a brief literature review. The data collection and research methods are explained in section 3 . The results will be discussed in section 4, followed by a discussion and conclusion of the study.

\section{A Brief Literature Review}

Food security has different interpretations and meanings and, over the years it has been regarded as a flexible concept (FAO, 2003). The importance of investigating food security has been well understood by the recent events of globalization and increasing global crises (Mcdonald, 2010:7). The global understanding of food security comprises of various concepts such as ecological, social, economic and political aspects that help to recognize the choices and problems that determine whether people have enough resources to consume the food they need and desire (McDonald, 2010:4). Global food security is associated with food systems that are characterised by the food chain activities of production, processing, distribution and consumption among different regions (Liver and Kapadia, 2010:24). This entails that globally sufficient food is produced to make it possible for national and sub-nationals to have access to sufficient food worldwide (Smith et al., 1992: 139).

National food security is defined within the context of national food self-reliance. It entails that a country is able to produce and distribute adequate food that is needed by all its citizens (Smith et al., 1992:140). National food security can be estimated by using the equal balance between food demand and food supply at an acceptable price. The unequal distribution of food demand and supply does not necessarily imply that all households within a country are food insecure; it simply means that a household is food insecure because they have limited entitlement to food due to inadequate resources (Thomson and Metz, 1999:3). A household is food secure when all members of its household have access to sufficient food needed to sustain them and live a healthy life (Tonukar and Omotor, 2010:1). This refers to the ability of a household to secure food, either from its own production or through purchases, adequate food for meeting the dietary needs of all members of the household (FAO, 2010). Andersen (2009:6) provides two reasons why households' food security may not guarantee food security for all its members; the ability to attain sufficient food may not be transformed into actual food attainment, and the intra-household distribution of the food may not meet the needs of each individual member of a household.

Food access suggests that every individual should have sufficient access to sufficient resources in order to have appropriate food to live a healthy life. Food accessibility by households can be obtained through consumption, production and receiving gifts from other households (FANTA, 2006:1). The extent to which each member of a household has access to sufficient food, depends on varies factors such as gender, age and the employment status (Benson, 2004:8). 
The purchasing power of households is the most critical determinant of access to food. The purchasing power depends on various pricing policies and market conditions (WFP, 2007:2). Several factors that have an effect on 'access to food' are at times misunderstood, and this has an adverse impact on the ability to identify appropriate polices to improve access to food (Alman et al., 2009). This is due to the multidimensional nature of the concept of food security. This at times leads to conflicting views about what being food insecure entails. Another challenge associated with measurement is that food security is based on assessments and behaviour and this requires identifying suitable methods, which might be difficult to find at times (Mohapatra et al., 2010:33).

\section{The Research Methodology}

\subsection{Survey area}

The geographical area covered by the study entails the area called Kwakwatsi. The area is a former black residential township located approximately $180 \mathrm{~km}$ south of Johannesburg and $280 \mathrm{~km}$ north of Bloemfontein in the Free State province of South Africa. The area is part of the Ngwathe Local Municipality, with its head office in Parys (Ngwathe Municipality, 2007). In South Africa, the term township and location usually refers to the often underdeveloped urban living areas that, from the late 19th century until the end of apartheid, were reserved for non-whites, principally Black and Coloureds. They were usually built on the periphery of towns and cities (Estelle, 2003). In the townships, households are caught in poverty trap from which they are unlikely to escape without government help. A large number of the population lives in these urban areas, which continue to grow at a rapid rate. Kwakwatsi is a former black residential township for the town of Koppies. The area could be classified as a semi-rural township, with little economic activity. The nearest industrial town of Sasolburg is $70 \mathrm{~km}$ away. The estimated population size of Kwakwatsi is 15095 (Ngwathe Municipality, 2009).

\subsection{Measuring food security}

A self-administered structured questionnaire was used to gather the required data for this study. The questionnaire included an existing scale used in previously published research. The household food insecurity access scale (HFIAS) developed by the USAID was used to measure vulnerability to food insecurity. There are two sub questions to the questionnaire, the first group of questions are called the nine occurrence questions and there are two response option available to the respondent 'yes' or 'no' (where no $=0$ and yes =1). The second group of questions refers to the nine frequency of occurrence questions; these questions are asked with the intention of making a follow-up to the occurrence questions and to establish whether the condition (food insecurity) ever occurred. Next to the 'no' response option there is a skip code, meaning the interviewer can skip the related frequency-of-occurrence follow-up question if the respondent answers 'no' to the occurrence question (Coates et al., 2007:2). The HFIAS score was calculated using the answers based on the nine frequency-of-occurrence questions. The scale takes a lowest score of 0 and the highest of 27; the higher the score the higher the probability of a household being vulnerable to food insecurity (USAID, 2007:8). According to the scheme recommended by the HFIAS indicator guide, the continuous score can be categorized into food secure and food insecure (Knueppel et al., 2009:363).

\subsection{Regression model}

The data for this study were collected in Kwakwatsi during April 2013. A total of 225 questionnaires were randomly administered in the area through face to face interviews. A multiple regression model was used to determine the socioeconomic and demographic factors affecting vulnerability to food insecurity. The regression model was estimated as follows:

$$
Y_{t}=\beta X_{t}+\varepsilon t
$$

Where $Y_{t}$ is unobserved, $X_{t}$ is vector of explanatory variables, and $\beta$ is the vector of unknown parameters; and $\varepsilon_{t}$ is the error term. The following socio-demographic characteristics are therefore hypothesized to influence household food security status: $\beta_{1}$ monthly household head income (in Rands), $\beta_{2}$ other household income, $\beta_{3}$ household size, $\beta_{4}$ age of the head of household, $\beta_{5}$ education attainment of the household head, $\beta_{6}$ marital status of the household head, $\beta_{7}$ and employment status of the household head. Household income is important as it determines how much can be spent on various needs of the household Household size is meant to account for the effects of household composition on food 
security. The age of the household head (in years) is selected as an explanatory variable in the study as both younger and older people are assumed to have differences in eating habits, lifestyles and opportunities to socialize. The gender, employment and marital status of the household head are important to consider as explanatory variables as the head plays a primary role in food purchasing and can influence the consumption patterns of a household. Formal education of the household head (in number of years) is another explanatory variable selected in this study due to its effect on lifestyles and health-related behaviour. Individuals with different levels of education may have different knowledge and perception about diet and health, and consequently may have different food requirements.

\section{Findings}

\subsection{The Demographic Characteristics of the Respondents}

In the analysis of the observations, households headed by males are separated from those headed by female and their results compared. The demographics and descriptive statistics of the respondents are reported in Table 1. From the total sample, 31 percent of all households were headed by a female. The results indicate that on average female heads received less monthly income (R1 551) than their male counterparts (R2 287). Furthermore, and despite the fact that both groups have the same number of employed persons per household (2), female-headed households received less additional income (Other_HH_Y = R1 533) compared to male-headed households (R2 133). The average household size was calculated at 4 for female-headed households, compared to 5 for households headed by a male. On average, both male and female household heads had primary schooling education.

Table 1: Descriptive statistics of the sample

\begin{tabular}{l|c|c|c}
\hline \multicolumn{1}{c|}{ Description } & Total HH & Female HH & Male HH \\
\hline Number of households & 225 & 68 & 156 \\
Head_Y & R2 061 & R1 551 & R2 287 \\
Other_HH_Y & R1 949 & R1 533 & R2 133 \\
HH_Size & 4 & 4 & 5 \\
Age_Head & 50 & 47 & 51 \\
Educ_Head & 5 & 6 & 5 \\
Married/living together (\%) & $71 \%$ & $25 \%$ & $91 \%$ \\
Unemployed (\%) & $27 \%$ & $26 \%$ & $28 \%$ \\
\hline
\end{tabular}

\subsection{The Food Security Status of Households in Kwakwatsi}

For the analysis of household food insecurity, the household food insecurity access scale (HFIAS) developed by the USAID was used to measure food security. The higher the HFIAS score the higher the probability of a household being vulnerable to food insecurity (USAID, 2007). The average HFIAS score was 3.49 (mildly food insecure access), with female-headed households recording a higher score (4.92) compared to 2.89 for male-headed households. Further analysis indicated that food insecurity is more prevalent among female-headed households ( $36 \%$ were food secure) than in male-headed households ( $57 \%$ were food secure). In total, $49 \%$ of the sampled households were found to be vulnerable to food insecurity. The extent of food insecurity can also be presented by ranking the scores of each household from food secure to severely food insecure. Figure 1 provides a comparison of the food in/security level of the two groups. The figure indicates an increased concentration of female-headed households ( $41 \%$ of $\mathrm{FHH}$ ) in the severely food insecure group. Overall these results suggest that determinants of food insecurity may vary with gender, but a further analysis is needed to confirm this. 
Figure 1: Food in/ security status by categories and gender

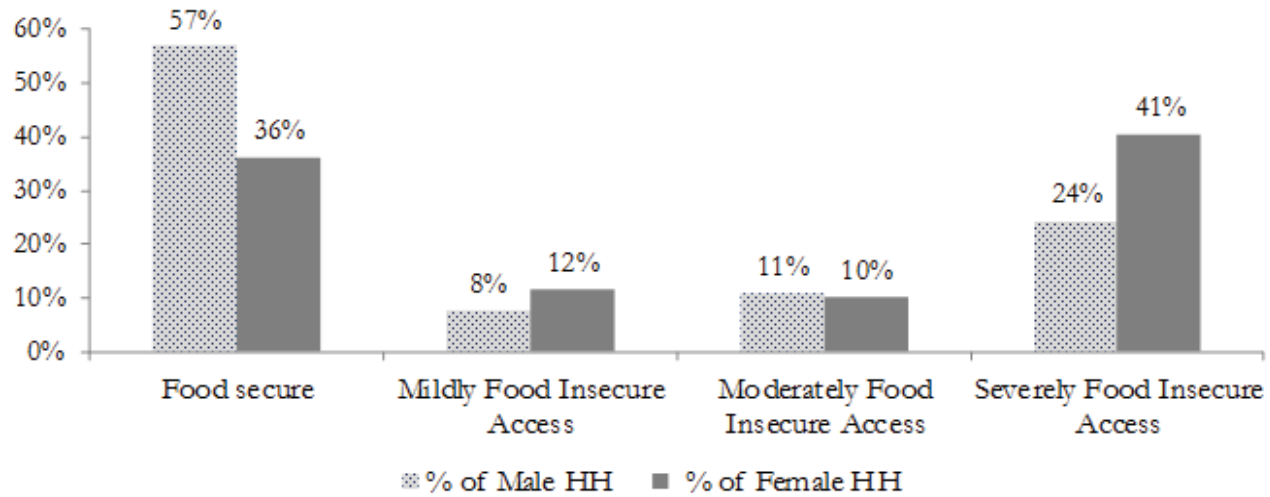

\subsection{Factors Affecting Household Food Security}

The results of the regression analysis are shown in table 2. These results provide strong support for earlier descriptive analysis. The results for male-headed households show that the coefficients of income (household head income and other household income), age of household head and the employment status of the household head are significant predictors of household food insecurity at different confidence levels. On the other hand, the results for female-headed households show that the coefficients of income (head income and other household income), household size, age and marital status of the household head are significant predictors of household food security. The positive sign of the coefficients indicates an increasing HFIAS score, thus indicating increased vulnerability to food insecurity. The results indicate that vulnerability to food insecurity would increase as the age of the household head increases. In femaleheaded households vulnerability to food insecurity increases as household size and age of the household head increases, and would also increase if the head of the household is married.

The variables that show a decrease in the vulnerability to being food insecure in male-headed households in Kwakwatsi are: household head income (Head_Y), income from other members of the household (Other_HH_Y) and employment status of the household head (ES_Head). The variables that decrease the vulnerability to being food insecure in female-headed households are: household head income (Head_Y) and income from other members of the households (Other_HH_Y).

Table 2: Factors affecting household food security

\begin{tabular}{|c|c|c|c|c|}
\hline & \multicolumn{2}{|c|}{ Male-headed households } & \multicolumn{2}{|c|}{ Female-headed households } \\
\hline & Coef. & Std. Err. & Coef. & Std. Err. \\
\hline Head Y & $-.0008768^{\star}$ & .000152 & $-.0012361^{*}$ & .0004377 \\
\hline Other $\mathrm{HH} Y$ & $-.0011089^{*}$ & .0002719 & $-.001149^{*}$ & .0004195 \\
\hline HH Size & .0704537 & .2387357 & $.7924953^{\star \star \star}$ & .4074133 \\
\hline Age Head & $.1033089^{*}$ & .0215418 & $.0810841^{\star *}$ & .0397018 \\
\hline Educ Head & .0769251 & .086222 & .2780203 & .1792561 \\
\hline ES_Head & $-2.361923^{*}$ & .8152582 & -1.530183 & 1.628491 \\
\hline Marital Head & -.5260307 & 1.023705 & $4.064497^{*}$ & 1.522537 \\
\hline & $\begin{array}{c}\mathrm{N} \\
\text { Prob> } \\
\mathrm{R}^{2}\end{array}$ & $\begin{array}{l}=156 \\
=0.000 \\
=0.4617\end{array}$ & $\begin{array}{c}\mathrm{N} \\
\text { Prob> F } \\
\mathrm{R}^{2}\end{array}$ & $\begin{array}{c}=100 \\
=0.000 \\
=0.5807\end{array}$ \\
\hline
\end{tabular}

* Significant at 1\% level, ** Significant at $5 \%$ level, ${ }^{* *}$ Significant at $10 \%$ level

\section{Discussion and Conclusion}

The aim of this study was to conduct a gender analysis of determinants of vulnerability to food insecurity in a South 
African township. The study employed USAID's household food insecurity access scale to determine the food security status of the sampled households. The average HFIAS score was 3.49, with female-headed households recording a higher score (4.92) compared to 2.89 for male-headed households. Further analysis indicated that food insecurity is more prevalent among female-headed households ( $36 \%$ were food secure) than in male-headed households ( $57 \%$ were food secure). In total, $49 \%$ of the sampled households were found to be vulnerable to food insecurity. A large number of female-headed households ( $41 \%$ of $\mathrm{FHH}$ ) were in the severely food insecure group, compared to $21 \%$ of male-headed households. Overall these results suggest that determinants of vulnerability to food security vary with the gender of the head of household.

The results of the regression analysis on the factors influencing vulnerability to household food security shows that an increase in household income decreases the chances of a household being food insecure in both male and femaleheaded households. This result is consistent with similar studies on food security, where household income is found to be the most important determinant of food security. A study by Bashir et al. (2012:4) in Pakistan found a positive relationship between the food security status of households and monthly income. Similarly, Jacobs (2009) concluded that low income households are more likely to suffer from food insecurity as compared to middle income and wealthier households. The employment status of the head of household in male-headed households was found to be negatively related to the probability of being food insecure. This variable was not significant in female-headed households. The age of the household head was positively related to the probability of being food insecure in both groups. The ageing of the household head might mean a decrease in income earning potential, thus increasing vulnerability to food insecurity

Household size and marital status of the head of household were associated with an increased probability of being food insecure in female-headed households. Larger household sizes require increased food expenditure and competition for limited resources. A study by Babatunde et al. (2007) concluded that larger household sizes are more likely to be food insecure than smaller size households. Jacobs (2009) notes that households with many members are expected to consume more food than small households. With regards to marital status, the results of this study differ from similar studies which conclude that married couples are more likely to be food secure (Elijah, 2010). A study by Kaloi et al., (2005) concluded that married couples were likely to be more food secure than single headed households. The purchasing power of households is the most critical determinant for food security through access to the means to acquire food. Specific programmes providing increase access to income earning possibilities would be needed to ensure a reduction in gender imbalances. The aim of this study was to highlight trends in terms of food security. Further analysis involved the identification of socio-economic and demographic factors likely to contribute to the probability of a household being food secure. The extent to which each household is food secure depends on various factors such as gender, age and the employment status. Further studies could be undertaken on a nationally representative sample in South Africa. There's also a need to explore the intra-household dynamics and their impact on food security.

\section{References}

Ackerman, G. (2012). Household incomes of poor eroded by rising food prices. [Online] Available: http://www.bdlive.co.za/opinion/ 2012/08/28/household-incomes-of-poor-eroded-by-rising-food-prices (30 August 2012).

Altman, M., Hart, T., \& Jacobs, P. (2009). Household food security status in South Africa. [Online] Available: http://www.ageconsearch.um.edu.pdf (15 November 2012).

Andersen, P. 2009. Food security: definitions and measurement. Food security, 1, 5-7.

Arene, C. (2008). Agricultural economics: a functional approach. Abuja: Price Publishers.

Babatunde, R., Omotesho, O., \& Sholotan, O. (2007). Socio-economic characteristics and food security of farming households in Kwara State, North-Central Nigeria. Pakistan Journal of Nutrition, 6(1), 41-58

Bashir, M., Schilizzi, S., \& Pandit, R. (2012). The determinants of rural food security: the case of landless households of Punjab, Pakistan. Crawley: The University of Western Australia.

Benson, T. (2004). African food and nutrition situation: where are we and how did we get here. Washington DC: International Food Policy Research Institute.

Carter, N.K., Lanumata, T., Kruse, K., \& Gorton, D. (2010). What are the determinants of food insecurity in New Zealand and does it differ for males and females. Wellington: Public Health Association of Australia.

Coates, J., Swindale, A., \& Bilinsky, P. (2007). Household food insecurity access scale for measurement of food access: Indicator Guide. Washington DC: Academy for Educational Development.

Crush J., Frayne, B., \& Pendleton, W. (2012). The crisis of food insecurity in African Cities. Journal of Hunger \& Environmental Nutrition, 7, $271-292$.

Department of Agriculture. (2002). Integrated food security strategy for South Africa. Pretoria: Government Publications.

Department of Agriculture, Forestry \& Fisheries. (2012). Food security policy of the Republic of South Africa. Pretoria: Government Publications. 
Du Toit, D.C., Ramonyai, M.D., Lube, P.A., \& Ntushelo, V. (2011). Food security. Pretoria: Production Economics Unit.

Ecker, O., \& Breisinger, C. (2012). Food security system: a new conceptual framework. Washington DC: International Food Policy Research Institute.

Elijah, O. (2010). Classification of households into food security status in the North-Central Region of Nigeria: an application of Rasch Mesurement Model. ARPN Journal of Agricultural and Biological Science, 5(3), 26-41.

Estelle, E. (2003). Poverty shocker for Cape Townships. [Online] Available: http://www.101.co.za/news/south.africa/poverty-shocker-forcape-townships-1,1150710 (24 Nov 2011).

Food and Agriculture Organization. (2003). Trade reform and food security: conceptualizing the linkages. Rome: United Nations' Food and Agriculture Organization.

Food and Agriculture Organization. (2010). The State of food insecurity in the world: addressing food in protracted crisis. Rome: United Nations' Food and Agriculture Organization.

FANTA (Food and Nutrition Technical Assistance). (2006). Food security. [Online] Available http://www.fanta.com (6 May 2013).

Frayne, B., Battersby-Lennard, J., Fincham, R., \& Haysom, G. 2009. Urban food security in South Africa: case study of Cape Town, Msunduzi and Johannesburg. Planning division working paper series No 15. Midrand: Development Bank of Southern Africa.

Jacobs, P. (2009). Identifying targets for household food security in South Africa. Pretoria: Centre for Poverty, Employment and Growth, Human Science Research Council.

Kaloi, E., Tayebwa, E., \& Bashaasha, B. (2005). Food security status of households in Mwingi district, Kenya. The 7th African Crop Science Society Conference, 5-9 December. Kampala, Uganda.

Kassie, M., Ndiritu, S.W., \& Shiferaw, S. (2012). Determinants of food security in Kenya: a gender perspective. [Online] Available: http://www.ageconsearch.umn.edu/bitstream/135124/2/simon\%2520Wagura_Ndiritu_gender-food\%2520-securityAES2012\%2520conference.pdf (22 March 2013).

Knueppel, D., Demment, M., \& Kaiser, L. (2009). Validation of household food insecurity access scale in rural Tanzania. California: Department of Nutrition.

Labadorios, D., Davids, Y.D., Mchiza, Z., \& Smith, G.W. (2009). The assessment of food insecurity in South Africa. Pretoria: Human Science Research Council.

Liverman, D., \& Kapadia, K., (2010). Food systems and global environment: an overview. In J Ingram, P Eriksen \& D Liverman. (Eds.), Food security and global environmental change (pp. 1-20). London: Earthscan.

Mcdonald, B. (2010). Food security. Malden: Polity Press.

Mohapatra, B.S., Koundal, K.R. \& Pal, S. 2010. Journal of food security. Gurgoun, Haryan: Institute of Food Security.

Ngwathe Municipality. (2007). Integrated development plan 2007-2012. Parys: Ngwathe Municipality.

Ngwathe Municipality. (2009). Integrated Development Plan Review 2009-2010. Parys: Ngwathe Municipality.

Smith, M., Pointing, J., \& Maxwell, S. (1992). Household food security, concepts and definitions: an annotated bibliography, development bibliography No 8, institute of development studies. Brighton: University of Sussex.

Statistics South Africa. (2011). Food security and agriculture, 202-2011. [Online] Available: http://www.statssa.gov.za (23 November 2012).

Thomson, A., \& Metz, M. (1999). Implications of economic policy for food security. Rome: Food and Agriculture Organization of the United Nations.

Tonukari, N.J., \& Omotor, D.G. (2010). Biotechnology and food security in developing countries. [Online] Available: http://academicjournals.org/bmbr/PDF/Pdf2010/Feb/Tonukari\%20and\%200motor.pdf (22 November 2012).

Van Zyl, J., \& Kristen, J. (1992). Food security in South Africa. Agrekon, 31, 1-15.

Von Braun, J., Bruis, H., Kumar, S., \& Pandaya-Lorch, N. (1992). Improving food security of the poor: concepts, policy and programs. Washington: International Food Policy Research Institute.

World Food Programme. (2007). Food assistance programming in the context of HIV. Washington DC: Food and Nutrition Technical Assistance Project for Educational Development. 
